Radionuclide contamination

\section{Nanometre-size products of uranium bioreduction}

0 strategy that is being pursued to tackle the international problem of actinide contamination of soils, sediments and water is to use microbial activity to 'fix' these radionuclides into an insoluble form that cannot be readily dispersed. Here we show that uraninite $\left(\mathrm{UO}_{2}\right)$ particles formed from uranium in sediments by bacterial reduction are typically less than 2 nanometres across and that the small size has important implications for uraninite reactivity and fate. Because these tiny particles may still be transported in an aqueous environment, precipitation of uranium as insoluble uraninite cannot be presumed to immobilize it.

The discovery that bacteria can convert mobile hexavalent uranium, $\mathrm{U}(\mathrm{VI})$, to tetravalent uranium, U(IV), which precipitates as uraninite $^{1}$, has spurred investigations into the in situ bioremediation of uraniumcontaminated groundwater. These strategies assume that the formation of highly insoluble uraninite ${ }^{2}$ will inhibit the mobilization of uranium.

We used organic substrates to create anaerobic conditions to stimulate growth of native bacteria in complex natural uraniumcontaminated sediments and water, taken from the Midnite Mine, Washington, USA. After 1 month, the aqueous uranium concentration decreased from 20 to 0.3 parts per million. Synchrotron-based uranium L-III edge X-ray absorption near-edge spectroscopy (XANES) analysis of the incubated sediment indicated that most U(VI) had been reduced to U(IV). Selectedarea electron-diffraction patterns and crystallographic analysis of two-dimensional transmission electron microscope (TEM) lattice-fringe images confirmed the structure as being that of uraninite (which is similar to that of calcium fluoride).

We also constructed a gene library encoding small-subunit ribosomal RNAs (16S rRNAs) from the incubated sediment ${ }^{3}$ to identify the bacterium that is likely to be responsible for the conversion of uranium to uraninite. Out of 94 clones, 42 clustered strongly with Desulfosporosinus spp. (results not shown), a Gram-positive sulphatereducing microbe. We confirmed that Desulfosporosinus spp. isolated from the sediment was able to reduce $\mathrm{U}(\mathrm{VI})$ to $\mathrm{U}(\mathrm{IV})$ and to precipitate $\mathrm{U}(\mathrm{IV})$ as uranium oxide (manuscript submitted).

Uraninite formed by mixed cultures in the incubated natural sediment, as well as by pure cultures of Desulfosporosinus spp., was characterized by high-resolution TEM (Fig. 1a). The uraninite crystals are less than $3 \mathrm{~nm}$ in diameter and occur as discrete
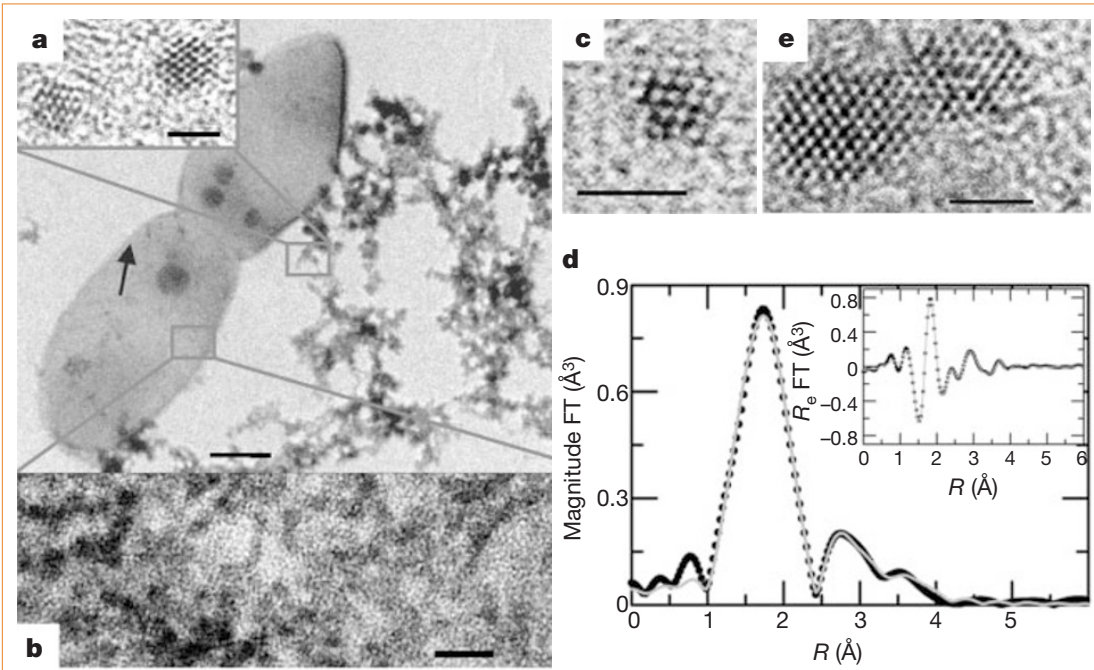

d

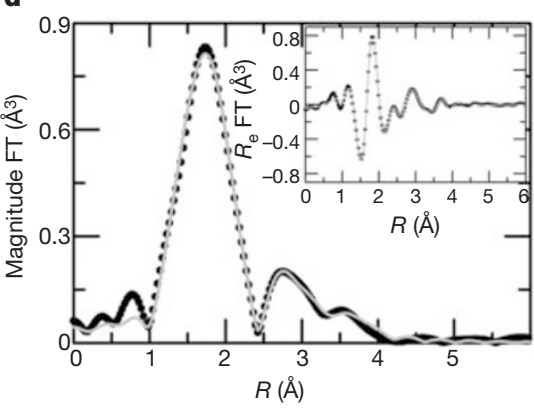

Figure 1 Characterization of bioreduced uraninite $\left(\mathrm{UO}_{2}\right)$ nanoparticles. a, Transmission electron microscopy (TEM) image of flocculated $\mathrm{UO}_{2}$ nanoparticles associated with Desulfosporosinus spp. bacteria (arrow). Inset, high-resolution TEM image of isolated particles. b, TEM image of the Desulfosporosinus cell surface coated with $\mathrm{UO}_{2}$ nanoparticles (size, $1.5-2.5 \mathrm{~nm}$ ). c, A single uraninite particle (about $1.3 \mathrm{~nm}$ across). d, Magnitude of the Fourier transform (FT) of X-ray-absorption fine-structure (XAFS) data obtained from the sediment, and the best-fit model. $R$, radial distance (uncorrected for electron phase shift). Inset, real part of the Fourier transform. $R_{e}$, real part of Fouriertransformed data. e, Growth of uraninite crystals formed by orientated attachment of individual nanoparticles. Scale bars: $0.6 \mu \mathrm{m}$ (a, inset, $2 \mathrm{~nm}), 6 \mathrm{~nm}(\mathbf{b})$ and $2 \mathrm{~nm}(\mathbf{c}, \mathbf{e})$

(Fig. 1a, inset) and aggregated particles, and as particle coatings on bacterial cell surfaces (Fig. 1b). Many crystalline particles were less than $1.5 \mathrm{~nm}$ in diameter (Fig. 1c), and our images indicated that even smaller particles were present (results not shown).

Extended X-ray-absorption fine-structure (EXAFS) analysis (Fig. 1d) of the incubated sediment revealed that the average uraninite U-U coordination number was $5.6 \pm 4$ (compared with 12 in bulk uraninite). This confirms that a large proportion of uranium ions in nanoparticles are at the surfaces of the uraninite nanoparticles, as expected for tiny particles. Structure models consistent with the EXAFS-determined coordination number imply an average particle size of about $1.5 \mathrm{~nm}$, which is close to the size of the smallest crystals detected in our highresolution TEM images. We conclude that bacterial U(VI) reduction produces uraninite particles in a range of sizes that extends down to molecular-scale clusters.

EXAFS data indicate that all U(IV) in the sediment was 8 -coordinated by oxygen, as in the bulk uraninite structure. U-U distances $(0.380 \mathrm{~nm})$ are $0.007 \mathrm{~nm}$ shorter in biogenic uraninite than in bulk uraninite, implying that there may be significant displacement of surface U(IV) ions. The $0.007-\mathrm{nm}$ contraction in $\mathrm{U}-\mathrm{U}$ spacing corresponds to a surface stress of about $4.82 \mathrm{~N} \mathrm{~m}^{-1}$, which represents more than a billion-fold increase in the solubility product compared with wellcrystallized uraninite ${ }^{4}$ (based on the reaction $\mathrm{UO}_{2}+2 \mathrm{H}_{2} \mathrm{O}=\mathrm{U}^{4+}+4 \mathrm{OH}^{-}$; the actual value depends on the quantitative relationship between surface stress and surface energy).

The nanometre-scale size of biogenic uraninite particles is likely to influence both its reactivity and transport. We would expect these $\mathrm{UO}_{2}$ crystals to be mobile in porous sediments and to re-oxidize rapidly. Flocculation, on the other hand, should reduce the transport potential. TEM images indicate that crystals grow from orientated aggregates of uraninite (Fig. 1e), which may be mediated in some cases by extracellular organic polymers (our unpublished results). To predict the likely environmental fate of $\mathrm{UO}_{2}$ nanoparticles, it will first be necessary to determine the transport physics of isolated nanoparticles and of nanoparticles adsorbed onto colloidal particles and organics, and to define models that link crystallization with crystal-growth kinetics, flocculation kinetics and fluid flow.

Yohey Suzuki $\aleph$, Shelly D. Kelly†, Kenneth M. Kemner $†$, Jillian F. Banfield ${ }^{\star}$

${ }^{*}$ Department of Geology and Geophysics, University of Wisconsin-Madison, Madison, Wisconsin 53706, USA

e-mail: jill@seismo.berkeley.edu

$\dagger$ Environmental Research Division, Argonne National Laboratory, Argonne, Illinois 60439, USA \$Department of Earth and Planetary Science, University of California, Berkeley, California 94720, USA

\$Present address: Japan Marine Science and Technology Centre, Yokosuka 237-006, Japan

\footnotetext{
Lovely, D. R., Phillips, E. J. P., Gorby, Y. A. \& Landa, E. R. Nature 350, 413-416 (1991).

2. Grenthe, I. et al. Chemical Thermodynamics of Uranium (Nuclear Energy Agency, North-Holland, The Netherlands, 1992)

3. Bond, P. L., Smriga, S. P. \& Banfield, J. F. Appl. Environ Microbiol. 66, 3842-3849 (2000).

4. Rai, D., Felmy, A. R. \& Ryan, J. L. Inorg. Chem. 29, 260-264 (1990).

Competing financial interests: declared none.
} 